\title{
Gerenciamento do portfólio de projetos (PPM): estudos de caso
}

\author{
Henrique Gonçalves de Castro ${ }^{\mathrm{a}}$, Marly Monteiro de Carvalho ${ }^{\mathrm{b}, *}$ \\ ahenrique00@uol.com.br, USP, Brasil \\ b,*marlymc@usp.br, USP, Brasil
}

\begin{abstract}
Resumo
0 artigo traz um levantamento dos principais modelos de gerenciamento do portfólio de projetos (PPM) e uma análise crítica para a construção do quadro teórico. Neste estudo, foram realizados quatro estudos de caso em diferentes setores, com o objetivo de identificar as principais práticas de PPM adotadas, o estágio de implementação e a relação entre as práticas e os resultados obtidos. Os principais resultados indicam que o PPM ainda é pouco presente nas organizações, e que a falta dele é um dos fatores que dificultam a implementação adequada das ações estratégicas definidas pelos executivos. 0 desdobramento das ações estratégicas em projetos e a delegação da responsabilidade pela execução dos projetos aos níveis inferiores, de forma desestruturada, promovem conflitos desnecessários, com perda de energia da organização.
\end{abstract}

Palavras-chave

Administração de projetos. Gerenciamento do portfólio de projetos. Seleção de projetos.

\section{Introdução}

A gestão de projetos possui três fases marcantes: a primeira, entre 1961 e 1990, quando ocorre o gerenciamento de projetos tradicionais; a segunda, a partir de 1990, com o gerenciamento de projetos modernos, marcado pela disseminação do guia de gerenciamento de projetos do Project Manegement Institute - PMl (1996, 2000, 2004, 2008). A terceira, com foco na organização e não no projeto, iniciada no final da década de 90, sobrepõe-se à segunda, concentrando seus esforços no desenvolvimento de competências e da maturidade em gerenciamento de projetos, com ênfase no alinhamento dos projetos à estratégia e na alocação eficaz dos recursos disponíveis, destacando a gestão de portfólio (RABECHINI Jr.; MAXIMIANO; MARTINS, 2005). Em 2006, o Project Management Institute divulgou um guia de PPM confirmando essa tendência (PMl, 2006).

Embora o campo de gestão de portfólio tenha origem na década de 50 , nos modelos de portfólio financeiro, os modelos de portfólio de projetos (PPM) surgem predominantemente nas áreas de pesquisa e desenvolvimento (P\&D) e desenvolvimento de novos produtos, nos anos 80 e 90 (DYE; PENNYPACKER, 1999; DE REYCK et al., 2005).

0 objetivo deste trabalho é montar um quadro analítico com base nos modelos e práticas (métodos, técnicas e ferramentas) de PPM disponíveis na literatura e confrontá-lo com as práticas de PPM adotadas pelas empresas, no estágio de implementação de PPM. A abordagem metodológica utilizada foi estudos de caso, realizados em quatro organizações.

Este artigo está estruturado em sete seções, contando com a introdução. A seção 2 apresenta uma síntese da revisão de literatura sobre PPM. Em seguida, a seção 3 mostra o quadro teórico proposto para análise da gestão de portfólio. $\mathrm{Na}$ seção 4 temos os principais aspectos metodológicos da pesquisa de campo. As Seções 5 e 6 apresentam os resultados dos estudos de caso e a discussão da pesquisa de campo, respectivamente. Finalmente, a seção 7 traz as conclusões e recomendações. 


\section{Síntese da literatura PPM}

0 gerenciamento do portfólio de projetos (PPM) tem se mostrado um tema de destaque desde os anos 90, assim como o portfólio de negócio nos anos 70 e 80 . Nesse período, foi elaborado o plano agregado de projetos (WHEELWRIGHT; CLARK, 1992; CLARK; WHEELWRIGHT, 1993) e foram realizados levantamentos sobre o portfólio de desenvolvimento de novos produtos (COOPER; EDGETT; KLEINSCHMIDT, 1997a, b), ao mesmo tempo em que as empresas americanas começaram a reconhecer que os princípios da gestão de projetos poderiam ser utilizados tanto para implementação quanto na operacionalização de planos estratégicos (KERZNER, 2002).

Kruglianskas (1992) foi um dos primeiros autores brasileiros a estudar as técnicas de portfólio na gestão de projetos, considerando que os recursos da empresa são limitados e os projetos devem alinhar-se com os objetivos dela.

O PPM tornou-se elemento-chave no sucesso das estratégias de longo prazo das organizações e está relacionado ao papel dos altos executivos e tomadores de decisões-chave, que devem validar os investimentos relevantes, além de formular e implementar metas e objetivos. No entanto, as técnicas estudadas são novas para as organizações. Como seus resultados não foram suficientemente testados, ainda não há consenso entre os executivos em relação à importância do PPM (COOPER; EDGETT; KLEINSCHMIDT, 1997a, b, 2001; COOPER et al., 2001; DYE; PENNYPACKER, 1999; ARCHER; GHASEMZADEH, 1999; DIETRICH; LEHTONEN, 2005).

Na visão de Rabechini Jr., Maximiano e Martins (2005), a complexidade inerente ao PPM faz com que poucas organizações tenham acesso a suas práticas e, consequentemente, a suas potencialidades. Para Roussel, Saad e Bohlin (1992), a estratégia de PPM pode ser mais bem aplicada naquelas organizações que gerenciam muitos projetos e precisam, portanto, de uma maneira mais profissional de administrar sistematicamente o conjunto de seus empreendimentos. No entanto, ainda há pouca evidência da prática estruturada de gestão de portfólio nas organizações (JEFFERY; LELIVELD, 2004).

Para entender a importância do gerenciamento de portfólio de projetos foi realizada uma pesquisa bibliográfica, a partir da qual foram encontradas mais de 400 fontes potenciais a partir de 1952 (DYE; PENNYPACKER, 1999; DE REYCK et al., 2005). Devido à inviabilidade de analisar um conjunto tão amplo de publicações, a ênfase foi para publicações lançadas a partir da década de 90, época em que a gestão de projetos começou a ganhar mais destaque nas organizações e no desenvolvimento da carreira dos profissionais de administração, engenharia e tecnologia da informação (DE REYCK et al., 2005).

Com base nos levantamentos da literatura, três desses modelos, desenvolvidos na década de 90 por Wheelwright e Clark (1992), Cooper, Edgett e Kleinschmidt (1997) e Archer e Ghasemzadeh (1999), destacam-se como referência na área de PPM.

Outros dois modelos pinçados da literatura são mais recentes - um deles é o guia de gerenciamento de portfólio do PMl (2006), selecionado pela penetração que o PMl tem nas organizações no Brasil. 0 outro modelo selecionado foi desenvolvido por Rabechini Jr., Maximiano e Martins (2005), que tem como base os três primeiros modelos e foi aplicado em uma empresa brasileira prestadora de serviços de interconexão eletrônica.

Para a análise comparativa dos cinco modelos de PPM foram considerados sete estágios: alinhamento com prioridades estratégicas, definição dos recursos, classificação dos projetos, avaliação individual, seleção e priorização dos projetos, alocação dos recursos e controle do portfólio. A síntese desta análise comparativa é apresentada no Quadro 1.

\section{Construção do quadro conceitual}

Nesta seção será apresentado o quadro teórico (framework) desenvolvido para esta pesquisa, que tem como base os cinco modelos analisados na fundamentação teórica desenvolvida na seção 2 .

Este framework é composto pelos sete estágios analisados na seção 2, divididos em três categorias. Essa divisão foi proposta com base em uma análise das características das atividades da empresa e da sua relação com os níveis de gestão estratégico, tático e operacional propostos por Anthony (1965). 0 nível estratégico contempla as atividades de planejamento estratégico, que definem o que deve ser feito, e são normalmente conduzidas pelos altos executivos. 0 nível tático contempla as decisões de como atingir os objetivos e as metas estratégicas. Uma vez que os objetivos e metas estratégicos estão estabelecidos, os gerentes intermediários decidem como atingi-los. Eles devem seguir as premissas definidas no plano estratégico e utilizar os recursos disponíveis na definição das ações que serão conduzidas pelo nível operacional. Nesse último nível, os gerentes de linha e os demais funcionários devem dar ênfase à execução no planejamento detalhado de cada projeto e na 


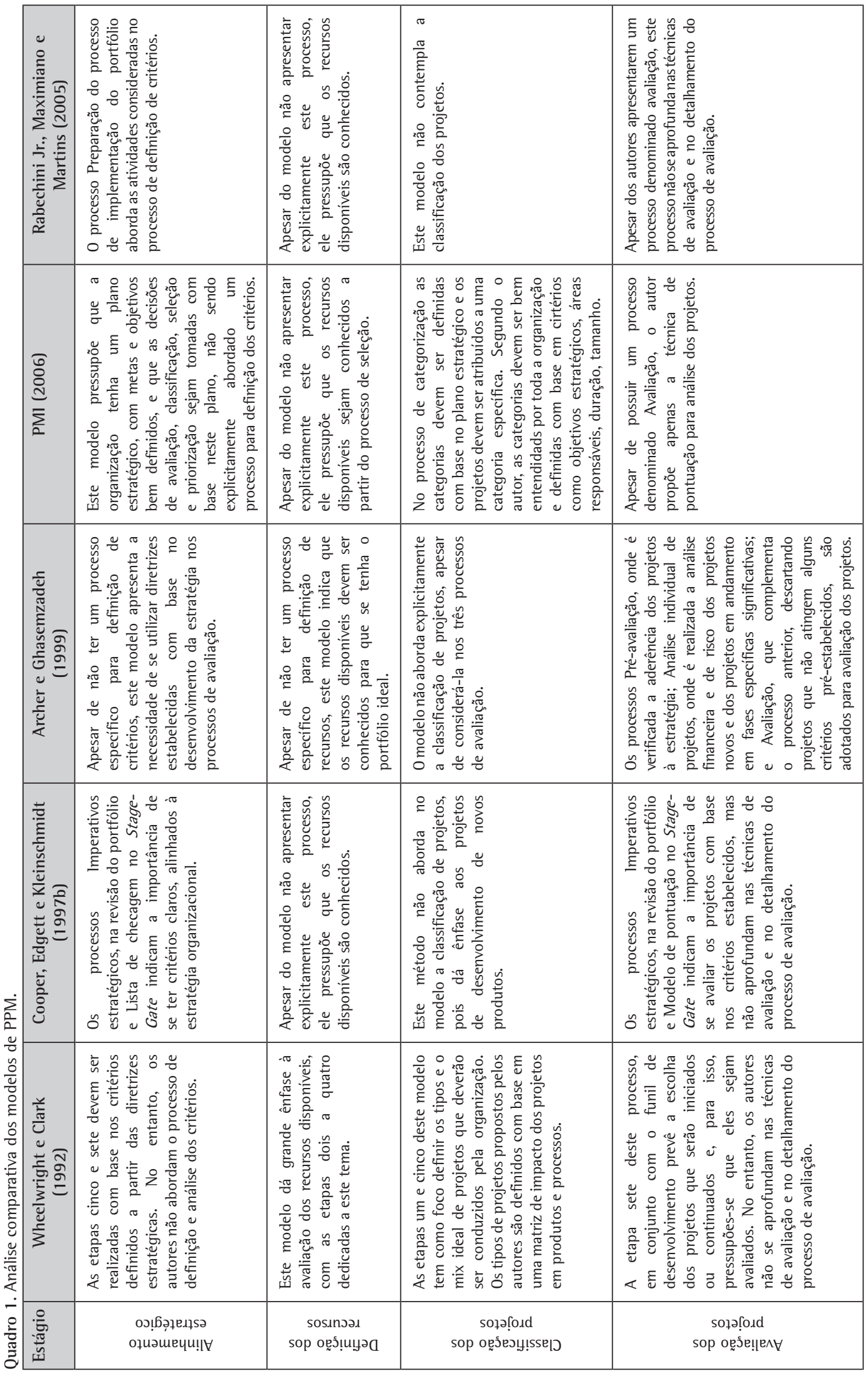




\begin{tabular}{|c|c|c|c|}
\hline 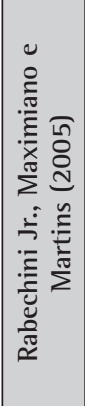 & 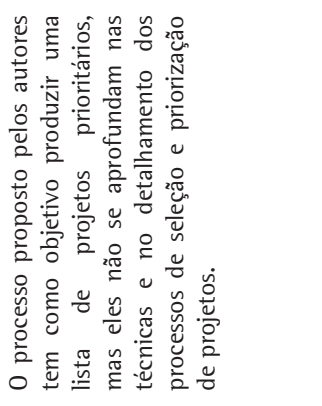 & 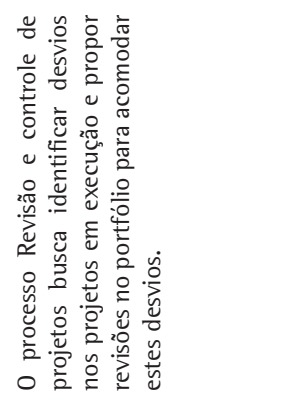 & 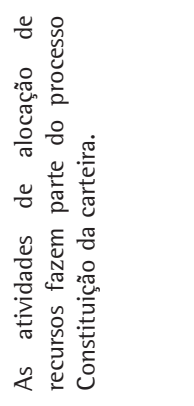 \\
\hline 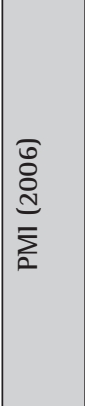 & 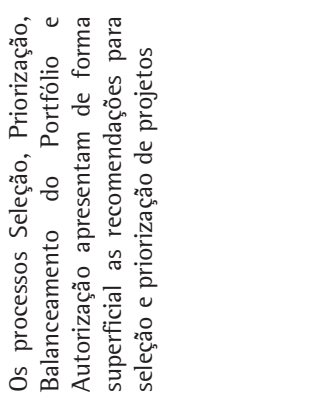 & 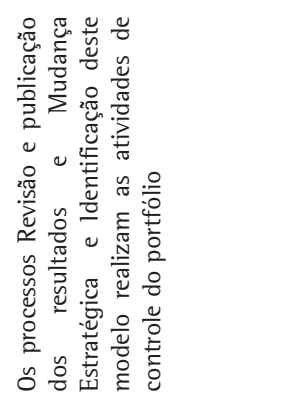 & 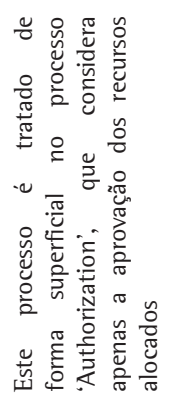 \\
\hline 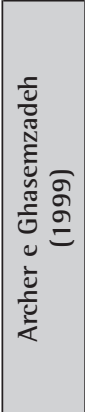 & 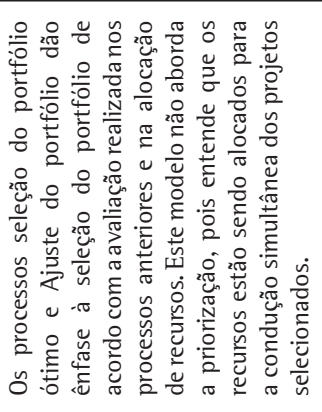 & 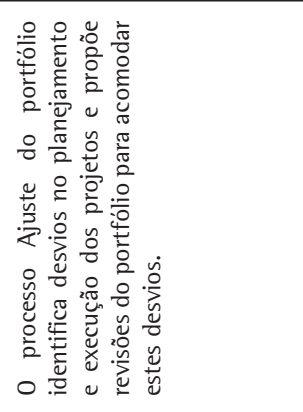 & 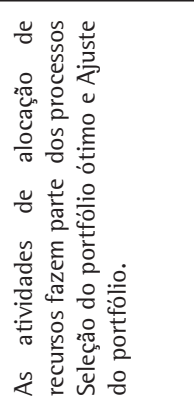 \\
\hline 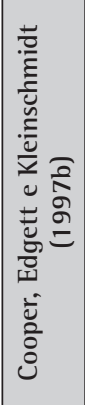 & 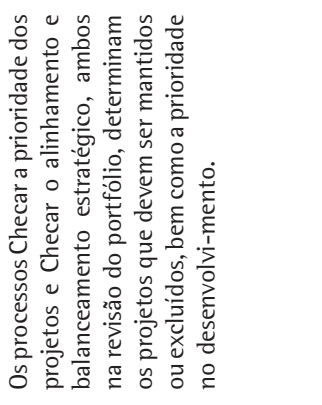 & 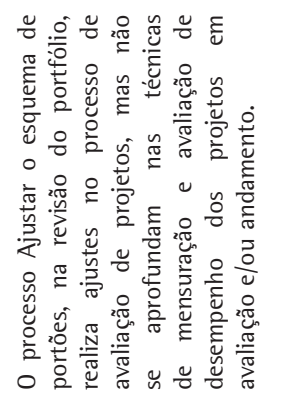 & 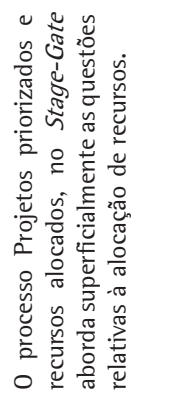 \\
\hline 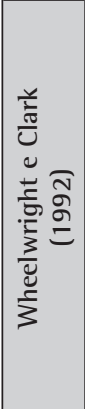 & 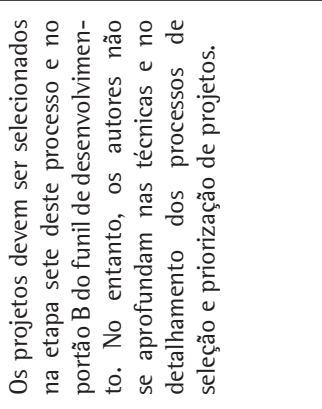 & 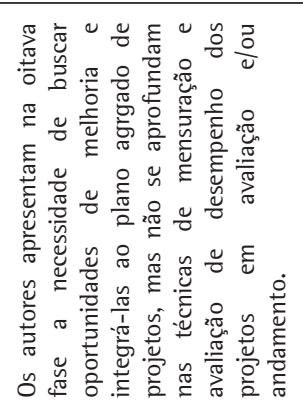 & 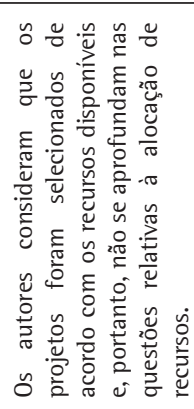 \\
\hline 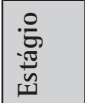 & 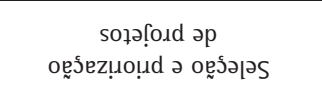 & 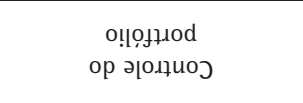 & 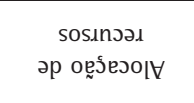 \\
\hline
\end{tabular}


execução das atividades (LOVE; IRANI; EDWARDS, 2003). Para esses autores, o nível operacional envolve a monitoração dos recursos utilizados em cada projeto e consiste em supervisionar, controlar e reportar as variações relacionadas às questões "quem?" e "quando?" no dia a dia dos projetos.

As atividades do PPM estão concentradas no nível tático, uma vez que visam identificar as ações que devem ser realizadas pela empresa para alcançar os objetivos e metas estratégicos, conforme apresentado na Figura 1. No entanto, há uma forte relação com o nível estratégico, no qual são definidos os objetivos e as metas, e com o nível operacional, onde os projetos são de fato executados. Dessa forma, os processos foram divididos nas seguintes categorias: fronteira do nível tático com o nível estratégico, nível tático e fronteira do nível tático com o nivel operacional.

Destaca-se que as atividades de desenvolvimento da estratégia, propostas de projetos, metodologia e atividades ligadas ao desenvolvimento de projetos não foram consideradas como parte do processo de PPM, não sendo por isso menos importante. 0 PPM relaciona-se com o desenvolvimento da estratégia por meio do processo definição de critérios, definição dos recursos e controle do portfólio. Já as propostas de projetos estão relacionadas ao PPM no momento em que precisam ser submetidas à avaliação. Elas são registradas e passam a fazer parte da base de projetos em avaliação. 0 desenvolvimento da metodologia alinha-se com todos os processos, uma vez que se considera fundamental a utilização de uma metodologia adequada à realidade da organização e a cada um dos processos. As atividades de desenvolvimento de projetos começam a ser aplicadas a partir do momento em que os recursos começam a ser alocados nos projetos, fazendo parte do nível operacional. Os projetos devem ser monitorados e encaminhados para revisão sempre que se desviarem dos parâmetros estabelecidos nos processos de seleção e priorização. Dessa forma, essas atividades se relacionam com as práticas de PPM por meio dos processos alocação de recursos e controle do portfólio.

\section{Abordagem metodológica}

Conforme mencionado na introdução deste artigo, os objetivos da pesquisa são:

- Elaborar um quadro teórico do PPM;

- Identificar as práticas de PPM adotadas pelas empresas;

- Identificar o estágio de implementação de PPM.

Dada a natureza exploratória desta pesquisa, adotou-se uma estratégia de pesquisa qualitativa, com abordagem de estudos de caso múltiplos, conforme ilustra a Figura 2.

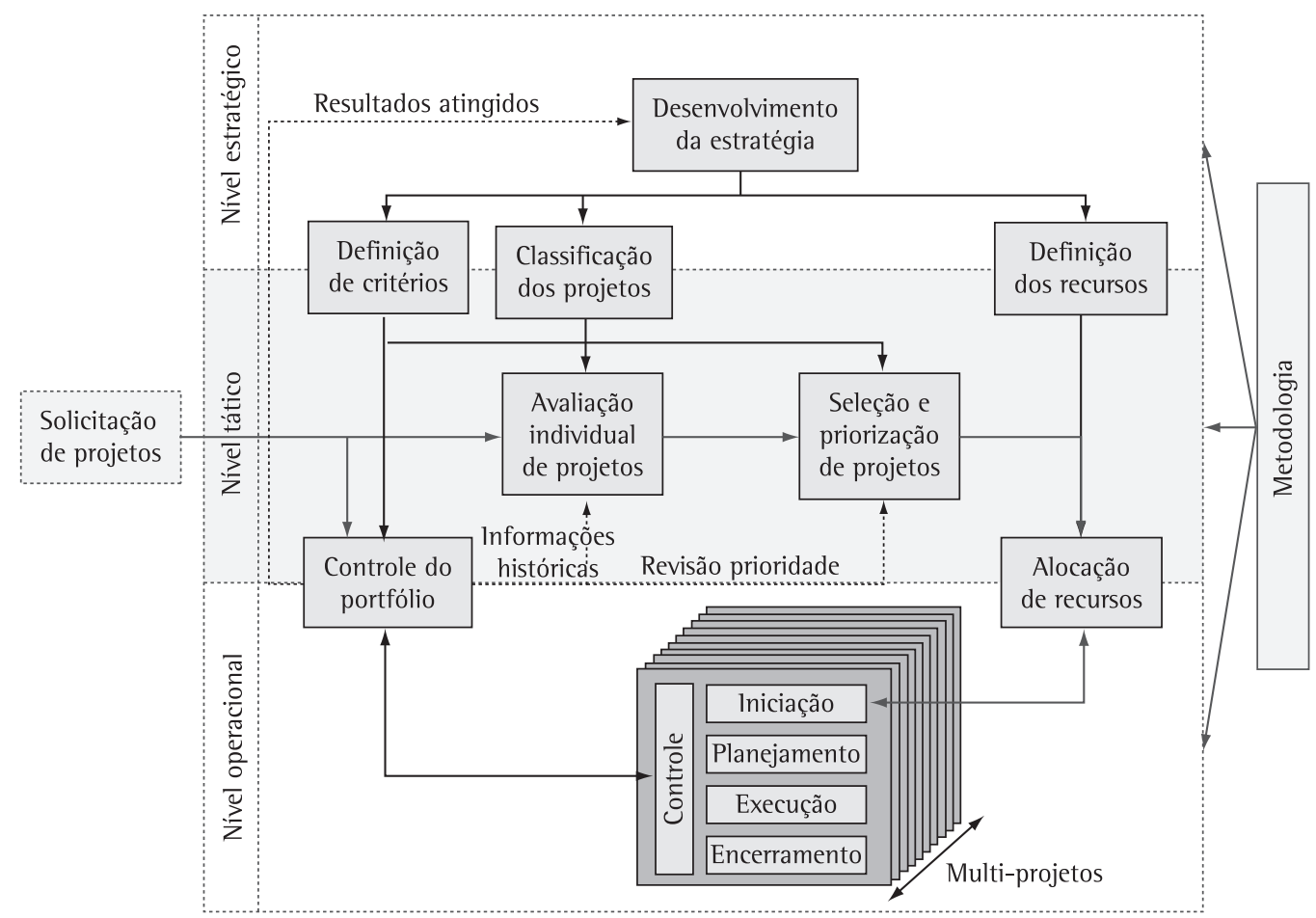

Figura 1. Quadro conceitual para análise do gerenciamento do portfólio de projetos (PPM). 


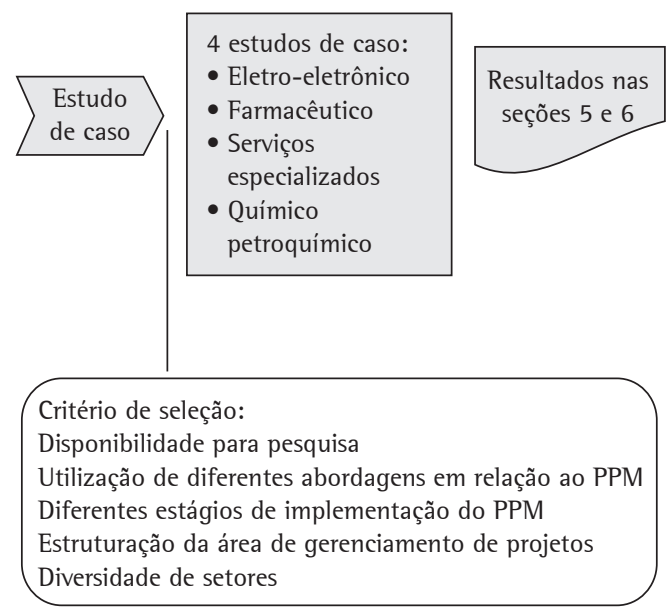

Figura 2. Projeto da pesquisa de campo.

Os critérios de seleção dos quatro casos estudados foram: disponibilidade para pesquisa, utilização de diferentes abordagens em relação ao PPM, e diferentes estágios de implementação do PPM conforme recomendação de autores de referência em pesquisas em organizações (YIN, 2005; HAIR Jr. et al., 2005).

\section{Apresentação dos resultados da pesquisa de campo}

Nesta seção será apresentada uma breve descrição do PPM em cada organização estudada, conforme os sete estágios definidos no quadro teórico, seguido da análise cruzada dos casos.

\subsection{Caso A: organização do setor eletroeletrônico}

Esta organização é uma multinacional do setor de eletroeletrônico com atuação nas áreas de telecomunicações, enterprise, serviços, indústria, energia e medicina. Essas áreas são subdivididas em 15 unidades de negócio, com faturamento em torno de R\$ 7 bilhões de reais no Brasil, no ano comercial 2005/2006, sendo que cerca de 50\% desse faturamento é proveniente da venda de projetos.

0 programa de gerenciamento de projetos da organização teve início em 2001 na matriz com ênfase nos projetos de clientes, que geram receita para a organização. A partir de 2008 será iniciado o desenvolvimento de uma metodologia específica para gestão dos projetos internos, como desenvolvimento de produtos e P\&D. Dessa forma, toda a análise que será realizada neste caso trata apenas do portfólio de projetos de clientes.
0 executivo entrevistado nesta organização é gerente do Escritório de Gestão de Projetos (Project Management Office - PMO) corporativo do Mercosul, tem 10 anos de formado e atua na organização desde então, tendo participado do grupo que iniciou o desenvolvimento do programa de gerenciamento de projetos em 2001. Além disso, é certificado pelo PMl como gerente de projetos.

\subsubsection{Alinhamento com as prioridades estratégicas}

É executado de forma separada por cada unidade de negócio. Anualmente cada uma realiza seu planejamento estratégico, onde são estabelecidas as diretrizes que vão nortear suas atividades a serem realizadas ao longo do ano. 0 entrevistado reforça: “Apesar de o planejamento não ser centralizado nem padronizado, ele é realizado por todas as unidades de negócio, direcionando a prospecção de novos projetos, bem como a decisão de apresentar ou não propostas para os projetos solicitados pelos clientes". 0 entrevistado entende que esse modelo de gestão dá a cada unidade autonomia para aperfeiçoar sua atuação em cada segmento, mas também destaca que a organização identificou a necessidade de aumentar a sinergia entre algumas áreas e realizar projetos multiáreas para atender a objetivos estratégicos da corporação.

Segundo o entrevistado, a seleção e priorização dos projetos internos são conduzidas pela matriz. Já para os projetos de clientes, esse processo é padronizado e ocorre durante a fase em que a organização elabora a proposta para uma determinada solicitação de um cliente. Nessa etapa, um dos critérios de avaliação é o alinhamento estratégico. "Normalmente, as equipes de vendas e relacionamento com clientes já direcionam a prospecção dos clientes para as questóes prioritárias a sua unidade de negócio, mas em alguns casos identificam oportunidades que não estão alinhadas." Segundo o entrevistado, esse é apenas um critério a ser avaliado, e a proposta pode ser encaminhada mesmo sem estar alinhada com os objetivos estratégicos. "Além da decisão de enviar ou não a proposta, esse critério dá subsídios para definição do preço a ser apresentado para o cliente."

\subsubsection{Definição de recursos disponíveis}

A organização entende que há dois tipos de recursos críticos: financeiros e humanos. Os recursos financeiros são avaliados de forma padronizada na fase onde a organização elabora a proposta para uma solicitação de um projeto de um cliente. "Em alguns 
casos precisamos levantar os recursos e financiar o projeto para o cliente", diz o entrevistado. Esses casos envolvem os altos executivos da subsidiária brasileira e, em algumas situações, precisam de aprovação da matriz. Já em relação aos recursos humanos, a organização busca desenvolver um conjunto de parceiros que podem ser alocados nos projetos de acordo com a necessidade, não sendo um caminho crítico para o PPM.

Uma das áreas que acompanham a alocação das equipes internas, a fim de identificar necessidades de contratação ou realocação de recursos entre seus departamentos, como exemplifica a Figura 3, com a alocação dos gerentes de projeto. A linha pontilhada indica a capacidade total dos recursos disponíveis, e a linha contínua assinala o nível de alocação com os projetos que estão no portfólio em curso. A parcela em cinza escuro mostra a quantidade de recursos alocada a categoria $A \& B$, que a área acompanha de forma segregada.

\subsubsection{Classificação dos projetos}

A classificação dos projetos de clientes ocorre de forma padronizada de acordo com quatro critérios (Quadro 2). A partir do preenchimento de um questionário, a ferramenta de cadastramento classifica o projeto em um dos seis diferentes níveis ( $\mathrm{A}$ a $\mathrm{F}$ ), que define quem deverá aprovar e monitorar o projeto em cada uma de suas fases. Os projetos classificados como A e B são monitorados pelo PMO corporativo. Essa carteira na região do Mercosul é composta por cerca de 200 projetos que representam uma receita em torno de $€ 1,0$ bilhão.
Os demais projetos são monitorados pelos seus gerentes e diretores de cada unidade de negócio.

\subsubsection{Avaliação dos projetos}

A principal etapa de avaliação de um projeto é durante a fase de elaboração, quando é tomada a decisão de apresentar ou não uma proposta para o cliente. "Uma vez apresentada uma proposta, a decisão está na mão do cliente. Se ele aceitar, nós vamos honrar o compromisso, pois o impacto de uma

Quadro 2. Critérios para avaliação e classificação de projetos no caso $A$.

\begin{tabular}{|c|c|}
\hline Critérios & Métricas \\
\hline Financeiros & $\begin{array}{l}\text { - Valor do projeto } \\
\text { - Risco financeiro } \\
\text { - Margem de lucro bruta } \\
\text { - Custo de engenharia e P\&D bruto } \\
\text { (\% da receita) }\end{array}$ \\
\hline Contratuais & $\begin{array}{l}\text { - Posição contratual (subcontractor, } \\
\text { sócio, joint-venture, etc) } \\
\text { - Quantidade de parceiros } \\
\text { - Quantidade de área de negócio } \\
\text { envolvidas } \\
\text { - Nível de relacionamento com o cliente }\end{array}$ \\
\hline Técnicos & $\begin{array}{l}\text { - Complexidade tecnológica } \\
\text { - Detalhamento do escopo } \\
\text { - Maturidade tecnológica }\end{array}$ \\
\hline Organizacionais & $\begin{array}{l}\text { - Tipo de projeto (fornecimento de } \\
\text { componentes, serviços técnicos, } \\
\text { sistema e soluções de fornecimento, } \\
\text { sistema Turnkey) } \\
\text { - Complexidade contratual } \\
\text { - Alinhamento estratégico } \\
\text { - Relevância estratégica para o cliente }\end{array}$ \\
\hline
\end{tabular}

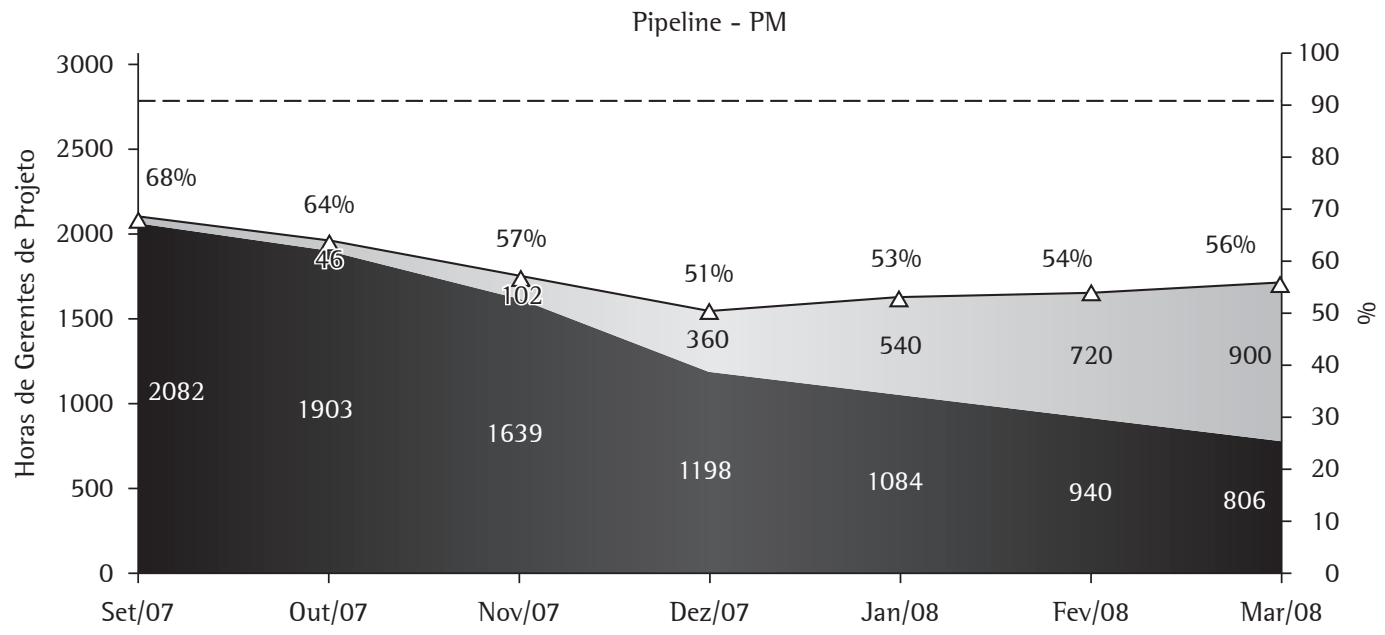

Pipeline

Total AB

Figura 3. Alocação dos gerentes de projetos de uma unidade de negócio da organização (fornecida pela empresa). 
desistência é muito negativo", diz o entrevistado. Para ele, tanto a decisão de realizar ou não uma proposta como a sua elaboração são de extrema importância para o sucesso na implementação dos projetos.

Nessa fase, além da decisão de entregar ou não a proposta, todos os projetos são avaliados minuciosamente. Para os casos mais complexos (projetos A e B), os diretores e o PMO corporativo se envolvem para garantir a qualidade da proposta. "O sucesso do projeto e a margem que vamos conseguir obter está diretamente ligada à qualidade da proposta", reforça o entrevistado. Apesar de utilizarem diversos critérios, conforme apresentado na Tabela 6.1 , as ferramentas mais utilizadas são financeiras, como a quantificação dos riscos envolvidos, do investimento realizado e da relação preço-margem. Os diagramas de bolha são utilizados em algumas situações para apoiar a análise financeira.

\subsubsection{Seleção e priorização dos projetos}

Nesta organização não é dada tanta ênfase na seleção e priorização dos projetos. Como o faturamento da organização está relacionado à quantidade de projetos que é capaz de fazer e a rentabilidade que consegue ter em cada projeto, a ênfase está na avaliação individual dos projetos, durante a fase de elaboração da proposta (como já foi explorado) e na otimização do processo de execução, foco da atuação do PMO corporativo. No questionário, a resposta em relação às práticas de PPM foi dada considerando a avaliação individual dos projetos, na fase de elaboração das propostas e o trabalho de controle do PMO sobre os projetos em execução e não em relação à seleção e priorização dos projetos como era esperado.

\subsubsection{Alocação dos recursos}

Os recursos necessários para execução do projeto ficam reservados ao período previsto para sua participação no projeto, desde o momento da apresentação da proposta ao cliente até o prazo para aprovação da proposta. Caso ela seja aprovada, a reserva é confirmada e os recursos são alocados efetivamente no projeto. Se for rejeitada, os recursos são liberados para serem usados em outros projetos. A composição de cada projeto cabe ao gerente do projeto, aos gerentes das áreas funcionais envolvidas e aos responsáveis pelo projeto nas empresas parceiras. Em caso de conflito a decisão é levada aos diretores envolvidos, que tomam a decisão.

\subsubsection{Controle do portfólio}

A organização não realiza controle centralizado do portfólio, durante as fases de elaboração das propostas e alocação dos recursos. Nestas etapas cada gerente comercial é responsável pelo envolvimento das pessoas que irão apoiá-lo na elaboração da proposta. Após a alocação da equipe, caso o projeto tenha sido classificado como $\mathrm{A}$ ou $\mathrm{B}$, o PMO passa a monitorar trimestralmente seus resultados. A principal medida de desempenho é a margem dos projetos, tanto seu valor bruto como sua variação em relação à margem estimada na fase de elaboração da proposta. Um dos relatórios produzidos pelo PMO e enviado ao CEO contém informações detalhadas dos dois melhores e dos três piores projetos. Normalmente ele convoca os responsáveis pelos três piores projetos para identificar o que gerou essa situação e quais ações podem ser tomadas para revertê-la.

Apesar da grande ênfase que a organização tem no controle do portfólio dos projetos em execução, esse controle não interfere diretamente na decisão de aprovar ou não um novo projeto, bem como não apoia o planejamento estratégico das unidades de negócio.

A Figura 4 sintetiza o PPM no caso A, que apresenta uma minuciosa avaliação dos projetos de clientes durante elaboração da proposta comercial e controle da execução pelo PMO .

\subsection{Caso B: organização do setor farmacêutico}

Esta organização é formada por uma jointventure entre três empresas do setor farmacêutico, com o objetivo de conduzir projetos de inovações radicais, tais como desenvolvimento de novas moléculas para o tratamento do câncer e redução da sensação de dor. 0 ciclo de vida de um projeto nesta organização é de 6 a 10 anos. Nos dois primeiros anos se realizam testes com animais, para garantir a segurança dos medicamentos, e nos anos seguintes são feitos testes com humanos para avaliar a eficácia dos medicamentos e compará-los com os existentes no mercado, atendendo os regulamentos da Agência Nacional de Vigilância Sanitária (ANVISA) do Ministério da Saúde.

Esta organização iniciou suas atividades em 2002, ano em que recebeu 20 propostas de projetos apresentadas por pesquisadores da área farmacêutica. Desses 20 projetos, quatro foram selecionados com base na qualidade das informações enviadas e na avaliação de especialistas. Dois anos 


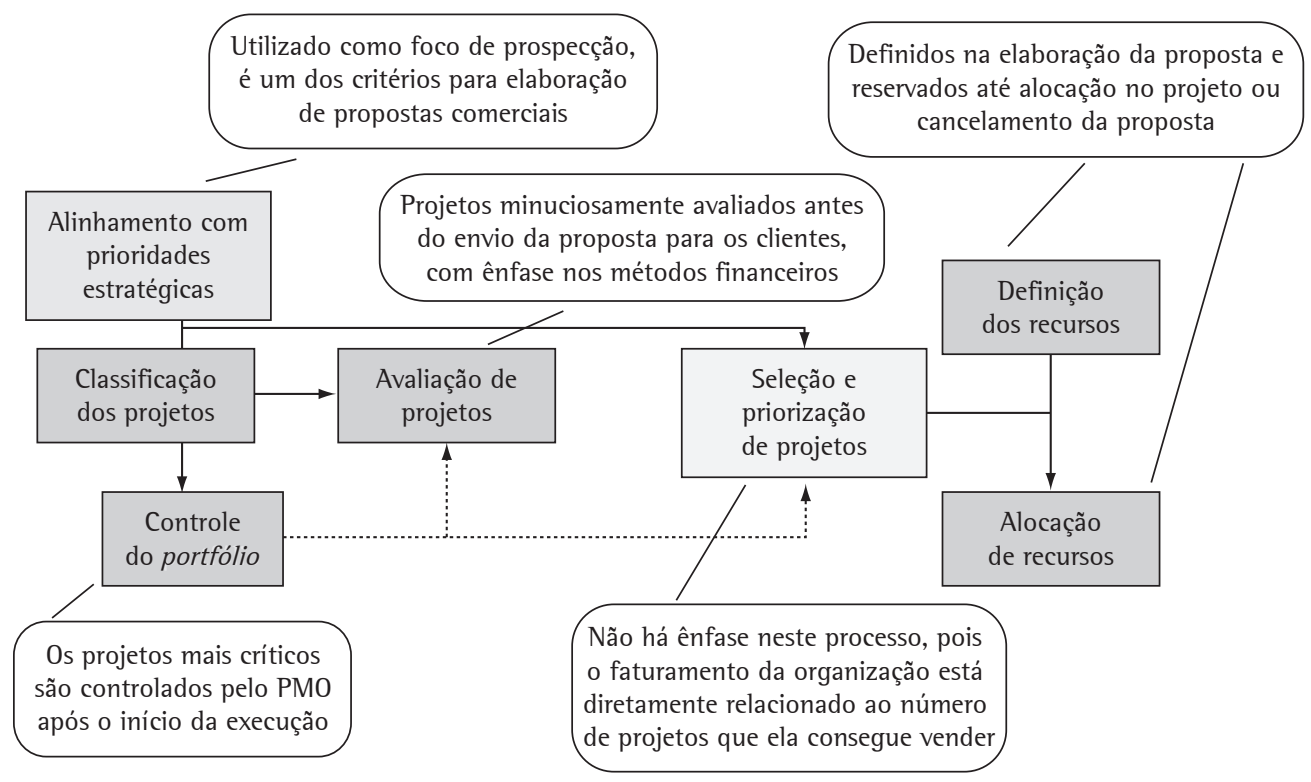

Figura 4. PPM no caso A.

mais tarde, em 2004, foi realizada nova rodada de seleção, com 12 propostas de projeto, sendo escolhidas duas, o que totalizou um conjunto de seis projetos no portfólio da organização. A partir desta data, foi interrompida a avaliação de novos projetos - para que se pudesse estruturar o fluxo de projetos e o método de avaliação deles -, que está sendo retomada no $2^{\circ}$ semestre de 2007 , já com o novo processo de avaliação.

0 entrevistado para o estudo de caso possui mestrado em gestão de inovação na Inglaterra. Atualmente ocupa o cargo de gerente executivo da organização avaliada, reportando diretamente ao comitê executivo constituído por diretores das três empresas sócias.

\subsubsection{Alinhamento com as prioridades estratégicas}

0 comitê executivo, composto por diretores das três empresas farmacêuticas sócias, definiu o critério de aceitação das propostas de projetos apresentadas e é responsável pela aprovação de todos os projetos em cada uma de suas etapas. Nesse momento, os diretores avaliam a qualidade individual de cada projeto e o benefício dele para suas organizações e dão parecer favorável ou não à sua continuidade. Segundo o executivo entrevistado, "Na fase inicial de aprovação os diretores estão mais preocupados em avaliar a consistência técnica dos projetos e garantir alinhamento com as classes terapêuticas e moléculas selecionadas".

\subsubsection{Definição dos recursos}

A definição dos recursos disponíveis também é realizada pelo comitê executivo a cada dois anos, com base em um planejamento orçamentário bianual para investimento nos projetos e na contratação de recursos internos para gestão dos projetos. A organização conta com uma equipe de 22 pessoas, em que cerca de 30\% tem dedicação parcial aos projetos aprovados, com atuação na prospecção de novos projetos e na avaliação das propostas, e $70 \%$ estão dedicados integralmente aos projetos já aprovados. Além dos recursos fornecidos pelos sócios, a empresa conta com recursos provenientes da FINEP e CNPq para reforçar o orçamento de alguns projetos.

\subsubsection{Classificação dos projetos}

Embora os projetos sejam classificados em aproximadamente seis categorias distintas, eles são gerenciados dentro de um mesmo portfólio, podendo haver realocação de recursos entre os projetos de acordo com a necessidade. 0 nome das categorias não foi revelado, pois trata-se de informação confidencial.

\subsubsection{Avaliação individual dos projetos}

A organização aplica uma metodologia desenvolvida com base no funil de desenvolvimento (CLARK; WHEELWRIGHT, 1993), apoiado por métodos financeiros, modelos de ponderação e 
checklists. Existem três fases de avaliação individual dos projetos.

$\mathrm{Na}$ primeira fase, que consiste na recepção e avaliação de propostas de projeto de pesquisadores, especialistas irão avaliar a possibilidade de gerar propriedade intelectual, além de considerar aspectos como investimentos necessários, tempo de maturação e riscos envolvidos. Os projetos aprovados terão cerca de dois anos nessa fase e, a partir daí, devem ser descartados ou aprovados para a segunda fase, quando serão realizados os testes com animais.

Durante essa fase serão investidos os recursos necessários para avaliar a segurança do medicamento, isolar e identificar o princípio ativo e realizar um plano de negócio detalhado que será utilizado como principal critério de avaliação da segunda etapa. Todos os resultados gerados neste período serão avaliados periodicamente pelo comitê executivo da organização, que pode suspender ou reduzir os investimentos, caso o resultado esteja abaixo do esperado. Para aprovação da segunda fase, o plano de negócio deve estar concluído para ser submetido à avaliação do comitê executivo. Esse plano é analisado criteriosamente, pois o investimento por projeto na terceira etapa é cerca de seis vezes maior que na segunda.

$\mathrm{Na}$ terceira fase, o processo de avaliação é mais objetivo, com indicadores de desempenho mais claros e com metas a serem cumpridas com os agentes reguladores. 0 primeiro projeto chegou a essa etapa recentemente e ainda não foi avaliado pelo comitê executivo.

\subsubsection{Seleção e priorização dos projetos}

Apesar do processo de avaliação estar bem desenvolvido, com a utilização de métodos financeiros, modelos de ponderação e checklists, não há um processo de seleção e priorização, onde os projetos do portfólio são comparados entre si. A organização entende que esse estágio ainda não é necessário, pois os recursos aprovados em orçamento têm sido suficientes para conduzir os projetos que passam pelos critérios de avaliação individual.

\subsubsection{Alocação de recursos}

A alocação dos recursos nos projetos tem sido feita com base no planejamento orçamentário de cada projeto e no acompanhamento dos gestores. Embora exista pouco conflito entre os projetos, algumas vezes foi necessário realocar recursos de um para outro para contornar ajustes no cronograma que alteraram o planejamento orçamentário. Essa decisão é tomada pelo próprio entrevistado, de acordo com seu julgamento sobre a prioridade de cada projeto.

\subsubsection{Controle do portfólio}

0 controle do portfólio é realizado pelo gerente executivo através de reuniões semanais com os gerentes de projeto. Semestralmente a evolução de cada projeto é apresentada ao comitê executivo, que pode decidir suspendê-lo.

A Figura 5 sintetiza o PPM no caso B, que utiliza o modelo de Wheelwright e Clark (1992) na avaliação dos projetos (destaque em cinza).

\subsection{Caso C: organização do setor de serviços especializados}

Esta empresa é do setor de serviços especializados, que atua como processadora de informações para empresas da área financeira, principalmente administradoras de cartão de crédito e financeiras. Ela fatura cerca de $\mathrm{R} \$ 700$ milhões por ano, tem 2.500 funcionários e é composta por três áreas de negócio: processamento de cartões, processamento de risco e relacionamento com o cliente, que engloba os processos de vendas, atendimento ao cliente e back-office.

Aproximadamente 15\% dos funcionários têm dedicação exclusiva a projetos e 50\% têm dedicação parcial. Sua estrutura de projetos é composta por um PMO corporativo e três diretorias de projetos, vinculadas às três áreas de negócio. 0 PMO tem o papel de monitorar a execução dos projetos, desenvolver metodologia e prover ferramentas de gerenciamento de projetos. Já as diretorias de projetos são compostas por gerências de equipe, que coordenam equipes de gerentes de projetos e atendem clientes específicos.

0 executivo entrevistado é o diretor responsável pelo PMO, com 15 anos de experiência em cartão de crédito e gestão de projetos.

\subsubsection{Alinhamento com as prioridades estratégicas}

A organização realiza um planejamento estratégico anual, onde estabelece as diretrizes para dimensionar as equipes de projetos que atenderão cada cliente e os investimentos que serão feitos nos projetos internos.

0 processo de alinhamento para os projetos de clientes é realizado em duas etapas. A primeira, antes do planejamento estratégico, com o objetivo de identificar as prioridades de cada cliente e a expectativa de investimento em novos projetos, que 
servirão de base para o planejamento estratégico. A segunda, após o planejamento estratégico, que tem como objetivo apoiar o cliente no planejamento de seus projetos.

Para garantir alinhamento dos projetos internos com os objetivos estratégicos da organização, existe o comitê de investimentos com representantes das áreas comerciais, áreas de negócio, PMO e controladoria, que avaliam mensalmente as propostas de projetos internos. Eles avaliam aderência aos objetivos estratégicos e o retorno financeiro esperado de cada projeto.

\subsubsection{Definição dos recursos}

Para os projetos de clientes, os recursos financeiros são definidos de acordo com a aprovação da proposta comercial pelo cliente. Os recursos humanos são divididos em dois grupos: recursos internos, previamente alocados às equipes que atendem cada um dos clientes, após o processo de planejamento estratégico, e os recursos externos, alocados durante a execução de cada projeto, conforme a necessidade.

Para os projetos internos, a definição de recursos é semelhante. A partir do planejamento estratégico, cada unidade de negócio tem um determinado orçamento para utilizar em seus projetos.

\subsubsection{Classificação dos projetos}

Os projetos são classificados de acordo com os seguintes critérios:
- Origem do financiamento: interno ou cliente externo;

- Área de negócio responsável: processamento de cartões, processamento de risco ou relacionamento com clientes (área com maior envolvimento);

- Envolvimento das áreas: monofuncional (apenas a área responsável) ou multifuncional;

- Tamanho: pequeno, médio ou grande (de acordo com o investimento, prazo e complexidade);

- Outras, de acordo com a necessidade de cada cliente.

A principal classificação para o PPM é a classificação da origem do financiamento, pois determina qual processo de priorização o projeto vai seguir. Os projetos com financiamento interno passam pelo comitê de investimentos, que aprova ou não cada projeto. Os projetos de cada cliente seguem fluxos próprios, adaptados a cada cliente.

\subsubsection{Avaliação dos projetos}

Os projetos internos passam por uma avaliação individual, onde é feito detalhamento técnico, levantamento dos investimentos necessários e dos benefícios que irá trazer. Uma síntese da avaliação é apresentada na reunião mensal do comitê de investimentos pelo gerente de negócio responsável. 0 comitê vai avaliar a consistência dos benefícios e o alinhamento com as diretrizes organizacionais e pode aprovar, rejeitar ou solicitar uma nova apresentação, com algum detalhe adicional, na reunião seguinte. Segundo o entrevistado, "[...] raramente um projeto

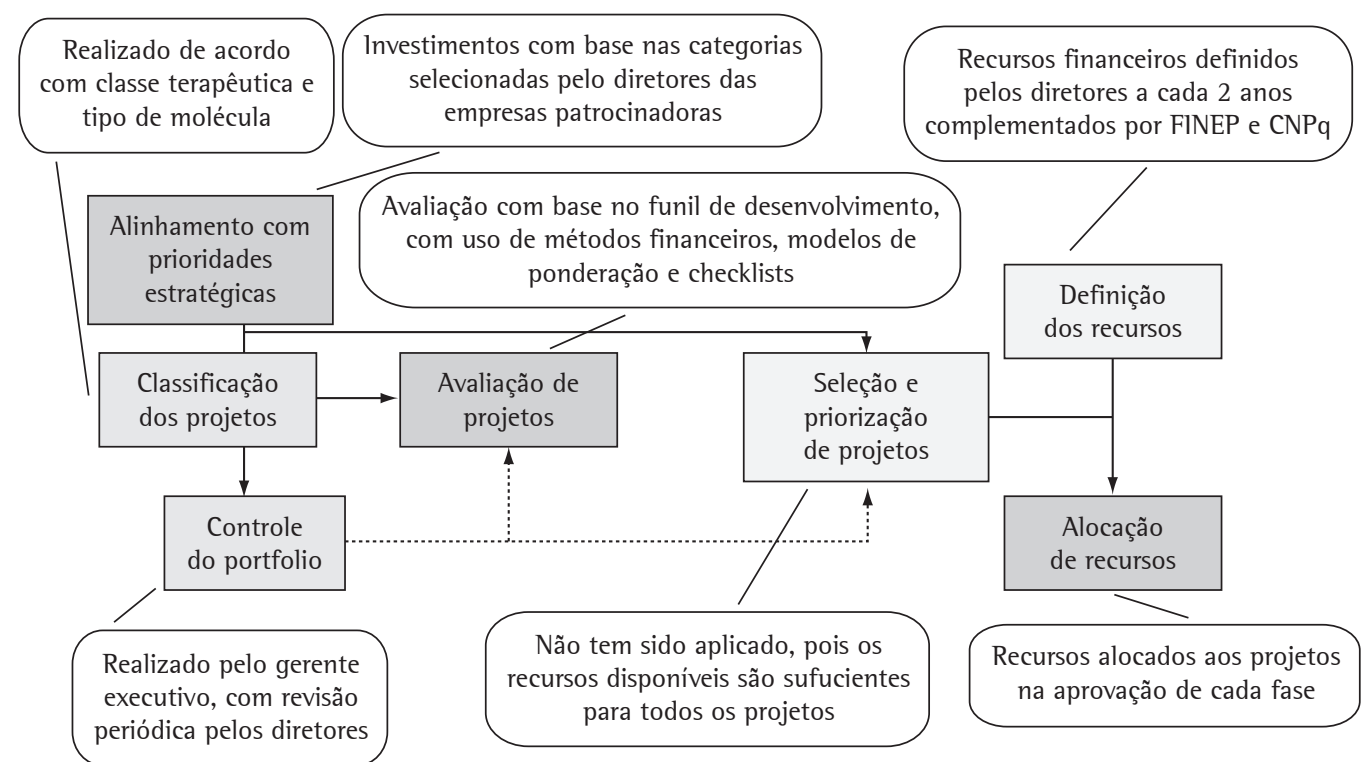

Figura 5. PPM no caso B. 
não é aprovado, pois o responsável alinha antes com os principais membros do comitê e, quando sente que terá problemas para aprová-lo, prefere não apresentar". Caso o orçamento do projeto não seja cumprido ou uma revisão do escopo seja necessária, o projeto deve ser novamente aprovado pelo comitê de investimentos.

Já a avaliação dos projetos de clientes ocorre durante a fase de elaboração da proposta comercial e segue processos específicos para cada cliente, de acordo com a informação solicitada na proposta. Segundo o entrevistado, alguns projetos envolvem os executivos das duas empresas e são avaliados em fórum específico. São normalmente projetos estratégicos para os clientes ou projetos de alta complexidade de desenvolvimento.

\subsubsection{Seleção e priorização dos projetos}

Para os projetos internos, a priorização não ocorre de forma adequada, principalmente quando se trata de projetos multifuncionais (envolve mais de uma unidade de negócio), o que gera conflitos na execução dos projetos e constante replanejamento das atividades e revisão de orçamento.

Para os projetos de clientes, esse processo depende, primariamente, do próprio cliente. 0 cliente Alpha tem um processo bem estruturado de seleção e priorização, que facilita a etapa de execução e minimiza os conflitos entre os projetos. Já o cliente Beta não realiza adequadamente a seleção e priorização dos projetos, o que provoca conflitos entre os projetos, que precisam ser solucionados durante sua execução, acarretando atrasos e revisões de escopo. "Como este cliente não tem restrições financeiras, ele aprova praticamente todas as propostas que apresentamos, inclusive algumas onde recomendamos que o projeto não fosse realizado, pois não viamos benefícios".

\subsubsection{Alocação dos recursos}

Os recursos devem ser alocados nos projetos de clientes conforme plano elaborado na proposta comercial, desde que esta esteja devidamente aprovada. No entanto, devido ao replanejamento dos projetos, ocorrem alterações nas demandas por determinados recursos durante a execução dos projetos, o que compromete a alocação destes nos demais clientes. Isto gera muitas vezes um efeito cascata, direcionando toda a atenção para um determinado projeto que está crítico.

\subsubsection{Controle do portfólio}

Esta organização tem um PMO que se envolve a partir do momento em que os projetos estão aprovados e registrados na ferramenta de gestão. 0 controle do portfólio em avaliação é acompanhado por cada unidade de negócio de forma não padronizada. 0 PMO monitora cerca de 300 projetos por ano, de diferentes categorias, mas com um papel bastante limitado. Segundo o entrevistado, o PMO gera relatórios semanais com base em informações registradas pelos solicitantes e pelos executores dos projetos de forma a dar visibilidade das divergências e forçar uma renegociação entre as áreas de negócio, responsáveis pela solicitação de projetos, e as áreas de $\mathrm{Tl}$, responsáveis pela execução dos projetos. Quando a divergência permanece acima do prazo estipulado, um alerta é submetido aos diretores que deverão intervir para solucionar o conflito. Segundo o entrevistado, diversos alertas ocorrem toda semana e, muitas vezes, os recursos são realocados entre os projetos para solucionar um conflito e logo em seguida surgem alertas nos projetos que perderam recursos.

0 PPM no caso C é pouco estruturado com excesso de projetos em execução, conforme sintetiza a Figura 6.

[...] a capacidade de mobilização desta empresa é inegável. A questão é que ela deixa pra fazer isso na crise, então enquanto um problema, um assunto não se torna um grande problema, ele vai rolando. Ele é um, é um leão que vai sendo alimentado. Então quando ele cresce e fica grande o suficiente para devorar quase todo mundo, ai sai todo mundo caçando ele... "então pega, pega, pega!!!" Aí mata! Não, aí mata! Mobiliza mata e, e, e aí dá outro [...]" (extraído da fala do entrevistado).

\subsection{Caso D: organização do setor de química e petroquímica}

Esta organização, de capital nacional, possui quatro unidades de produção no Brasil e duas no exterior e R\$ 1 bilhão de faturamento em 2006, intensiva em capital e sede em São Paulo. Ela atende mais de 40 países, dos cinco continentes, com matéria-prima e serviços ligados às indústrias químicas e petroquímicas, com aproximadamente 1.000 funcionários, dos quais 10\% atuam em projetos e P\&D. 0 portfólio de projetos tem pouco mais de 100 projetos com um valor total em torno de $\mathrm{R} \$ 600$ milhões.

0 executivo entrevistado é um dos coordenadores de projeto, com 18 anos de experiência na organização avaliada.

\subsubsection{Alinhamento com prioridades estratégicas}

0 planejamento estratégico da organização ocorre no terceiro trimestre de cada ano, onde são 


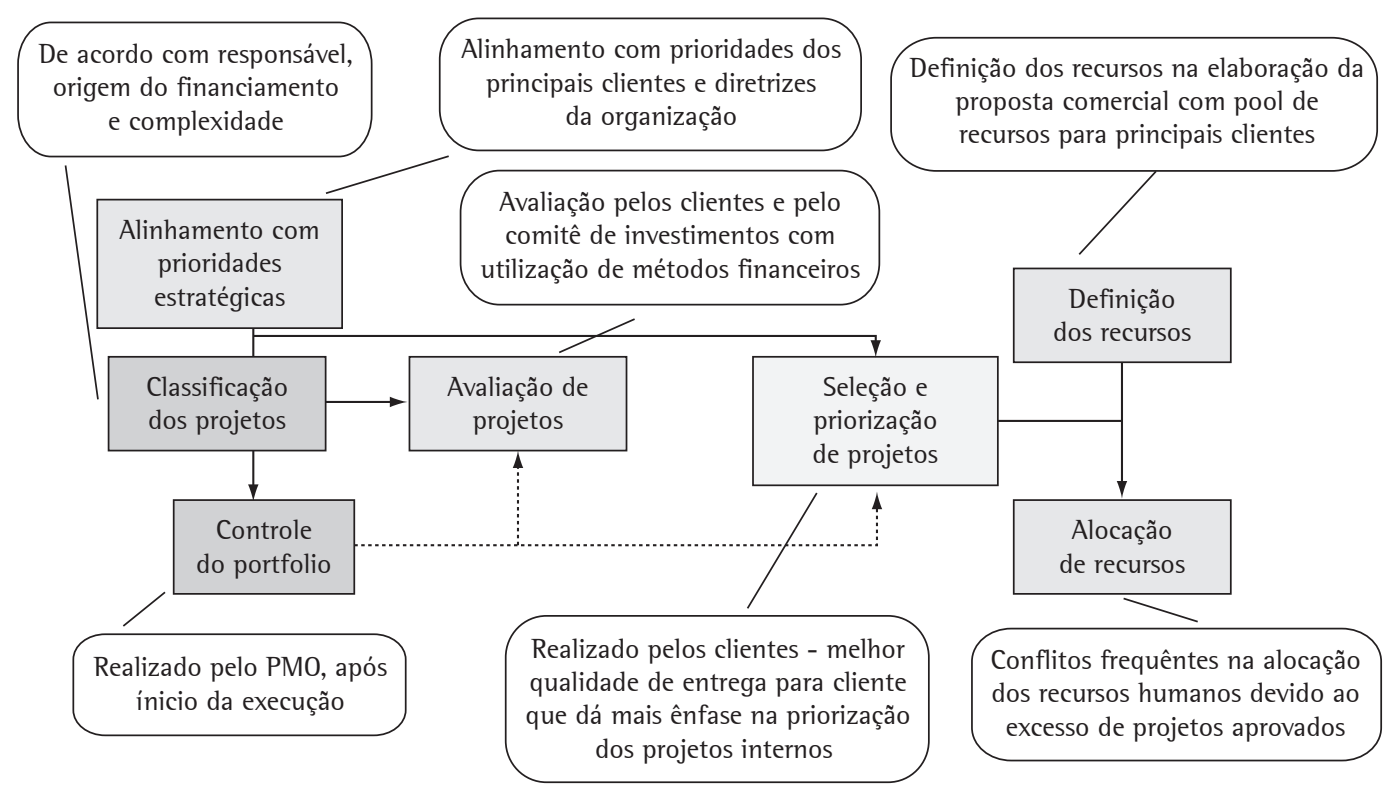

Figura 6. PPM no caso C.

avaliadas as tendências de mercado e as necessidades internas de desenvolvimento para os próximos três anos. A partir do plano de ação decorrente do planejamento estratégico, cada área desenvolve seu plano de ação para o ano seguinte, com todos os projetos que pretende implementar, que devem ser submetidos à análise de um comitê de diretores, para aprovação.

\subsubsection{Definição dos recursos}

Paralelo ao processo de planejamento ocorre o processo de definição do orçamento para o ano seguinte, de forma que a aprovação pelo comitê de diretores esteja vinculada a um orçamento estipulado para cada projeto. No entanto, a disponibilidade de recursos humanos capacitados para execução dos projetos não é considerada, o que levará a conflitos na alocação dos recursos e na execução dos projetos.

\subsubsection{Classificação dos projetos}

Os projetos são classificados de acordo com sua natureza, tipo e característica. Em relação à natureza, são divididos em estratégicos e operacionais. Quanto ao tipo, são classificados em (i) aquisições de serviços ou propriedades, (ii) manutenção de equipamentos ou sistemas $\mathrm{e}$ (iii) instalação de novos equipamentos, sistemas, unidades ou plantas. Há ainda a classificação em 11 tipos de projetos segundo suas características, conforme segue: capacidade de produção, novos produtos, redução de custos, administrativos, tecnologia de informação, segurança industrial, qualidade, fim de vida útil, estudos de viabilidade preliminar e modernização de instalações.

\subsubsection{Avaliação dos projetos}

Os projetos operacionais são submetidos ao diretor industrial para aprovação após avaliação pelos gestores com base na classificação, descrição, objetivos, cronograma físico e financeiro e análise financeira.

Os projetos estratégicos são avaliados pelo comitê executivo, que aprova seu início, e monitorados mensalmente pelo diretor e gerente da área responsável. Em alguns casos, consultorias e especialistas externos são contratados para analisar esses projetos e supervisionar sua implementação, com aprovação destes pelo conselho de acionistas.

\subsubsection{Seleção e priorização de projetos}

Como o orçamento é determinado para cada planta da empresa, os diretores agrupam os projetos operacionais por planta para selecionar os projetos que, na sua visão, melhor contribuem para atingir as metas da organização. Não há uma definição clara da prioridade dada aos diversos projetos operacionais aprovados. Segundo o entrevistado, espera-se que os projetos estratégicos sejam prioritários em relação aos operacionais de alto 
retorno, que por sua vez sejam prioritários quanto ao demais, mas na prática, todos competem pelos mesmos recursos. Segundo o entrevistado, "no dia a dia, o que vale é o relacionamento pessoal do gerente do projeto com as pessoas que ele precisa para avançar [...] muitas vezes um gerente com bom relacionamento consegue atenção dos recursos críticos, quando estes deveriam estar direcionados a projetos mais importantes".

Como não há um processo sistematizado de priorização, ela acaba ocorrendo de maneira informal. No final do ano, quando o resultado de cada projeto é apresentado, que se percebe que projetos mais importantes foram prejudicados em função de outros não tão significativos.

\subsubsection{Alocação de recursos}

Esse é o maior desafio da organização, segundo o entrevistado, devido à aprovação de projetos sem levar em consideração os recursos existentes e à falta de priorização dos projetos selecionados. Como os projetos são aprovados sem considerar a capacidade de execução da organização, a demanda por eles está sempre acima da capacidade dos recursos existentes.

Os diretores partem do princípio que, tendo os recursos financeiros aprovados, os gerentes têm condições de contratar as pessoas necessárias para conduzir os projetos. No entanto, na opinião do entrevistado, há restrição de profissionais no mercado capacitados para conduzir os projetos da organização. "Temos várias posições em aberto para contratar, mas como o mercado está muito aquecido e a pressão aqui está grande, ao invés de contratar, estamos perdendo gente", reforça o entrevistado.

Além da dificuldade para alocar os recursos nos projetos aprovados no planejamento anual, alguns projetos são aprovados por exceção ao longo do ano e incluídos no portfólio de projetos, sem revisão dos recursos disponíveis para conduzir esses projetos. Consequentemente, aqueles que estão em execução precisam ser replanejados para acomodar os projetos adicionais sem alteração dos recursos.

0 impacto disso é o atraso de alguns projetos e perda de qualidade em outros. Conforme apresentado em Padovani et al. (2006), dois dos quatro projetos estratégicos analisados foram implementados com atraso e os seis projetos operacionais com maior orçamento foram implementados no prazo, mas apresentaram sérios problemas de qualidade, como:

- Desativação precoce, devido a mudanças no mercado;
- Necessidade de expansão logo após implementação, devido a crescimento inesperado;

- Necessidade de melhorias, devido à superficialidade da especificação de requisitos.

\subsubsection{Controle do portfólio}

Não é realizado controle corporativo do portfólio de projetos. A cada final de ano é designada uma equipe para atualizar as planilhas e produzir um book, a ser apresentado aos diretores, com o resultado e estágio de cada projeto. 0 trabalho apresentado por Padovani et al. (2006) foi um estudo de caso único, cujas informações sobre os projetos tiveram que ser garimpadas pela organização através de entrevistas e análise de diversos relatórios produzidos de forma não padronizada.

A Figura 7 sintetiza o PPM no Caso D, que tem PPM pouco estruturado, com alta demanda por recursos especializados e pouca clareza das prioridades, o que gera conflitos e atrasos na execução.

\section{Discussão dos resultados: análise cruzada dos casos}

Para facilitar a análise dos quatro casos estudados, nesta seção será apresentada uma análise comparativa das organizações estudadas e dos respectivos PPM em face dos sete estágios analisados. 0 Quadro 3 apresenta o perfil dos casos estudados e o Quadro 4 sintetiza a análise cruzada.

\subsection{Alinhamentos com prioridades estratégicas}

As organizações dos casos B e D realizam essa etapa de forma satisfatória. Nos casos A e C, como uma parcela importante dos projetos é oriunda de demandas de cliente, e fonte importante de receita, o alinhamento às prioridades fica limitado. No caso A é utilizado como foco para as áreas comerciais, e no caso $\mathrm{C}$ é feito um esforço para que os projetos estejam alinhados com as estratégias dos clientes.

\subsection{Definições dos recursos}

Nos casos A e C, os recursos são definidos com base no orçamento elaborado para apresentação de proposta comercial aos clientes. No entanto, a organização do caso A apresentou um processo mais estruturado para essa etapa, com uma gestão mais 
Quadro 3. Perfil dos casos estudados.

\begin{tabular}{|c|c|c|c|c|}
\hline & Caso A & Caso B & Caso C & Caso D \\
\hline Setor & Eletroeletrônicos & Farmacêutico & $\begin{array}{c}\text { Serviços } \\
\text { especializados }\end{array}$ & $\begin{array}{c}\text { Químico / } \\
\text { Petroquímico }\end{array}$ \\
\hline Origem do capital & Estrangeiro & Nacional & Nacional & Nacional \\
\hline \begin{tabular}{|l} 
Faturamento anual do Brasil, \\
aproximado (R\$)
\end{tabular} & 7 bilhões & Não há & 700 milhões & 1 bilhão \\
\hline Número de funcionários & 8.000 & 22 & 2.500 & 1.000 \\
\hline $\begin{array}{l}\text { Valor aproximado da carteira de } \\
\text { projetos }\end{array}$ & $\begin{array}{l}\mathrm{R} \$ 3,5 \text { bilhões com } \\
\text { projetos de clientes }\end{array}$ & $\mathrm{R} \$ 2$ bilhões & Não informado & $\mathrm{R} \$ 600$ milhões \\
\hline Tem PMO? & Sim & Não & Sim & Não \\
\hline Realiza PPM de Forma padronizada? & Sim & Sim & Não & Não \\
\hline \multicolumn{5}{|l|}{ Alinhamento } \\
\hline \multicolumn{5}{|l|}{ Definição de recursos } \\
\hline \multicolumn{5}{|l|}{ Classificação dos projetos } \\
\hline \multicolumn{5}{|l|}{ Avaliação dos projetos } \\
\hline \multicolumn{5}{|l|}{ Seleção e priorização dos projetos } \\
\hline \multicolumn{5}{|l|}{ Alocação dos recursos } \\
\hline \multicolumn{5}{|l|}{ Controle de portfólio } \\
\hline \multicolumn{5}{|l|}{ Legenda: } \\
\hline \multicolumn{5}{|c|}{ Estágio do PPM mais estruturados confrontando-se com a leitura. } \\
\hline \multicolumn{5}{|c|}{ Estágio do PPM parcialmente estruturados confrontando-se com a literatura. } \\
\hline Estágio do PPM não estruturado. & & & & \\
\hline
\end{tabular}

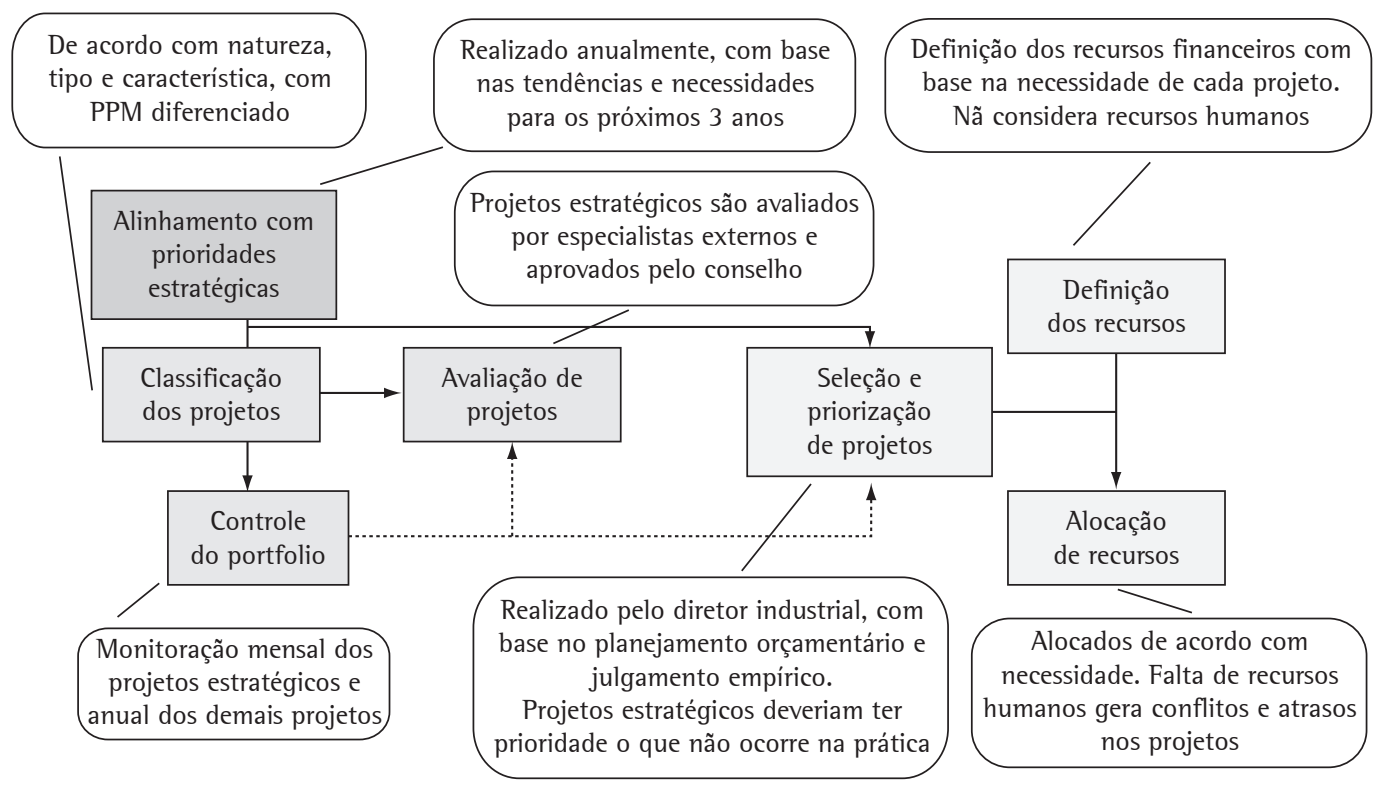

Figura 7. PPM no Caso D.

efetiva do pool de recursos disponíveis. O caso B aloca os recursos de acordo com a necessidade de cada projeto e ainda apresenta pouco conflito por recursos entre os projetos. 0 caso $\mathrm{D}$ aloca os recursos financeiros de forma eficiente, mas não considera a restrição de recursos humanos capacitados para condução dos projetos, o que prejudica a implementação efetiva dos projetos selecionados.

\subsection{Classificações dos projetos}

Realizado de forma satisfatória em todos os casos. É interessante reforçar que a classificação é feita de forma bem específica em cada organização. Nos casos A e C há um primeiro nível comum, com base na origem do financiamento (interno ou cliente), que determina fluxos de decisões diferenciados. 
Quadro 4. Características do PPM nos casos estudados por estágio.

\begin{tabular}{|c|c|c|c|c|}
\hline Estágio & Caso A & Caso B & Caso C & Caso D \\
\hline 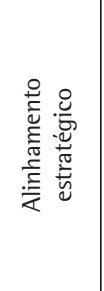 & $\begin{array}{l}\text { É utilizado na definição do } \\
\text { foco das áreas comerciais e } \\
\text { como um dos critérios para } \\
\text { elaboração das propostas } \\
\text { comerciais. No entanto, } \\
\text { podem ser encaminhadas } \\
\text { propostas não alinhadas às } \\
\text { prioridades estratégicas. }\end{array}$ & $\begin{array}{lr}\text { Projetos são alinhados } \\
\text { com objetivos estratégicos, } \\
\text { com base nas categorias } \\
\text { selecionadas para } \\
\text { investimento e aprovação } \\
\text { dos diretores. }\end{array}$ & $\begin{array}{l}\text { Maior preocupação em } \\
\text { alinhar os projetos com } \\
\text { prioridades dos principais } \\
\text { clientes. Os projetos internos } \\
\text { devem ser aprovados em } \\
\text { comitê de investimentos, que } \\
\text { deve zelar pelo alinhamento } \\
\text { com as prioridades } \\
\text { estratégicas da organização. }\end{array}$ & $\begin{array}{l}\text { A maioria dos projetos é } \\
\text { decorrente do planejamento } \\
\text { estratégico anual que } \\
\text { considera as tendências } \\
\text { e necessidades para os } \\
\text { próximos três anos. }\end{array}$ \\
\hline 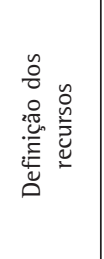 & $\begin{array}{l}\text { São definidos na fase de } \\
\text { elaboração da proposta e } \\
\text { reservados até a alocação } \\
\text { nos projetos ou liberação }\end{array}$ & $\begin{array}{l}\text { Recursos definidos pelos } \\
\text { diretores a cada dois anos, } \\
\text { complementados por } \\
\text { recursos do FINEP e CNPQ }\end{array}$ & $\begin{array}{l}\text { Recursos financeiros e } \\
\text { contratação de recursos } \\
\text { externos definidos durante } \\
\text { elaboração da proposta } \\
\text { comercial e pool de recursos } \\
\text { humanos internos alocados } \\
\text { para cada cliente com base } \\
\text { no planejamento anual }\end{array}$ & $\begin{array}{l}\text { Os recursos financeiros } \\
\text { são definidos com base } \\
\text { na necessidade de cada } \\
\text { projeto. A disponibilidade } \\
\text { de recursos humanos } \\
\text { capacitados não é } \\
\text { considerada. }\end{array}$ \\
\hline 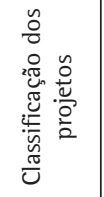 & $\begin{array}{l}\text { Padronizada de acordo } \\
\text { com critérios de tamanho } \\
\text { e complexidade, com base } \\
\text { em questionário respondido } \\
\text { pelo gerente comercial }\end{array}$ & $\begin{array}{l}\text { De acordo com a classe } \\
\text { terapêutica e tipo de } \\
\text { molécula }\end{array}$ & $\begin{array}{l}\text { De acordo com origem } \\
\text { do financiamento, área } \\
\text { de negócio responsável, } \\
\text { envolvimento das demais } \\
\text { áreas, tamanho e critérios } \\
\text { específicos para cada cliente }\end{array}$ & $\begin{array}{l}\text { Classificados por natureza, } \\
\text { tipo e característica, com } \\
\text { PPM diferenciado para } \\
\text { os projetos de natureza } \\
\text { estratégica e operacional }\end{array}$ \\
\hline 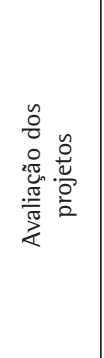 & $\begin{array}{l}\text { Projetos são } \\
\text { minuciosamente avaliados } \\
\text { antes de enviar a proposta } \\
\text { para os clientes, com ênfase } \\
\text { na utilização de métodos } \\
\text { financeiros. }\end{array}$ & $\begin{array}{l}\text { Projetos são avaliados em } \\
\text { trêsmomentosdiferentes, de } \\
\text { forma muito semelhante ao } \\
\text { funil do desenvolvimento, } \\
\text { com utilização de métodos } \\
\text { financeiros, modelos de } \\
\text { ponderação e checklists. }\end{array}$ & $\begin{array}{l}\text { Projetos de clientes são } \\
\text { avaliados pelos próprios } \\
\text { clientes com base em } \\
\text { informações levantadas } \\
\text { pela organização. Nível de } \\
\text { detalhe acordado com cada } \\
\text { cliente, Projetos internos } \\
\text { são avaliados pelo comitê } \\
\text { de invstimento com Ênfase } \\
\text { na utilização de métodos } \\
\text { financeiros. }\end{array}$ & $\begin{array}{l}\text { Projetos estratégicos são } \\
\text { avaliados por especialistas } \\
\text { com base em diversos } \\
\text { critérios e submetidos ao } \\
\text { conselho de acionistas } \\
\text { para aprovação; Projetos } \\
\text { operacionais são avaliados } \\
\text { pelos gerentes e submetidos } \\
\text { para aprovação do diretor } \\
\text { industrial }\end{array}$ \\
\hline 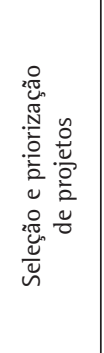 & $\begin{array}{l}\text { Não há ênfase neste } \\
\text { estágio, pois o objetivo da } \\
\text { organização é aumentar o } \\
\text { volume de projetos, que está } \\
\text { diretamente relacionado ao } \\
\text { faturamento e rentabilidade } \\
\text { da organização. }\end{array}$ & $\begin{array}{l}\text { Ainda não é aplicado } \\
\text { uma vez que os recursos } \\
\text { aprovados tem sido } \\
\text { suficientes para conduzir } \\
\text { os projetos aprovados } \\
\text { pelos critérios de avaliação } \\
\text { individual. }\end{array}$ & $\begin{array}{l}\text { Projetos de clientes são } \\
\text { selecionados e priorizados } \\
\text { pelos mesmos. Comparando } \\
\text { os dois principais clientes, } \\
\text { o que dá mais ênfase nesta } \\
\text { etapa, tem menos revisões } \\
\text { de escopo e menos atraso } \\
\text { nos projetos. Os projetos } \\
\text { internos também não } \\
\text { são priorizados de forma } \\
\text { adequada. }\end{array}$ & $\begin{array}{l}\text { Seleção realizada por um } \\
\text { únco diretor, com base em } \\
\text { planejamento orçamentário } \\
\text { e julgamento empírico; } \\
\text { Projetos estratégicos } \\
\text { deveriam ter prioridade, } \\
\text { mas na prática não } \\
\text { funciona adequadamente }\end{array}$ \\
\hline 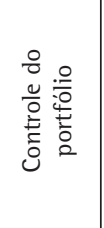 & $\begin{array}{l}\text { Os projetos com maior } \\
\text { grau de criticidade são } \\
\text { controlados pelo PMO } \\
\text { após início da execução; } \\
\text { Os demais projetos não } \\
\text { são controlados de forma } \\
\text { centralizada. }\end{array}$ & $\begin{array}{l}\text { Realizado pelo gerente } \\
\text { executivo e apresentado aos } \\
\text { diretores periodicamente }\end{array}$ & $\begin{array}{l}\text { Realizado pelo PMO após } \\
\text { início da execução, com } \\
\text { consolidação semanal dos } \\
\text { indicadores de desempenho } \\
\text { e envio de relatório com } \\
\text { principais desviosaosdiretores } \\
\text { e gerentes envolvidos. }\end{array}$ & $\begin{array}{l}\text { Projetos estratégicos são } \\
\text { monitorados mensalmente } \\
\text { pelos diretores; Projetos } \\
\text { operacionais a cargo dos } \\
\text { gerentes responsáveis, com } \\
\text { revisão anual dos resultados } \\
\text { atingidos }\end{array}$ \\
\hline 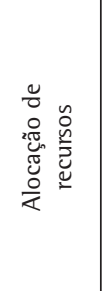 & $\begin{array}{l}\text { Recursos financeiros } \\
\text { e humanos são pré- } \\
\text { alocados na entrega da } \\
\text { proposta para o cliente e } \\
\text { confirmados na aceitação } \\
\text { da proposta; Equipe } \\
\text { composta por recursos } \\
\text { internos ou terceiros, } \\
\text { conforme necessidade. }\end{array}$ & $\begin{array}{l}\text { Realizado conforme } \\
\text { planejamentoorçamentário, } \\
\text { a medida que os projetos } \\
\text { são aprovados; Ajustado } \\
\text { pelo gerente executivo } \\
\text { conforme necessidade. }\end{array}$ & $\begin{array}{l}\text { Realizado pelo gerente } \\
\text { responsável } \\
\text { aprovação; Conflitos são } \\
\text { comuns devido ao excesso } \\
\text { de projetos aprovados por } \\
\text { alguns clientes e falta de } \\
\text { priorização dos projetos } \\
\text { internos. }\end{array}$ & $\begin{array}{l}\text { Recursos humanos } \\
\text { distribuídos e acordo com } \\
\text { funçãoealocadosnosprojeos } \\
\text { conforme necessidade; } \\
\text { Falta de recursos humanos } \\
\text { capacitados para atender } \\
\text { todos os projetos, gera } \\
\text { conflitos e atrasos na } \\
\text { execução dos projetos. }\end{array}$ \\
\hline
\end{tabular}


Quadro 4. Características do PPM nos casos estudados por estágio.

\begin{tabular}{|c|c|c|c|c|}
\hline Estágio & Caso A & Caso B & Caso C & Caso D \\
\hline 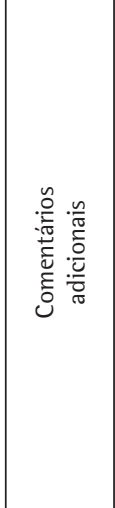 & $\begin{array}{l}\text { Como esta organização } \\
\text { tem faturamento } \\
\text { diretamente relacionado ao } \\
\text { desenvolvimento de projetos, } \\
\text { seu processo de PPM } \\
\text { está focado na avaliação } \\
\text { individual dos projetos de } \\
\text { clientes durante a elaboração } \\
\text { das propostas e no } \\
\text { acompanhamento criterioso } \\
\text { do PMO na execução } \\
\text { dos projetos de maior } \\
\text { criticidade para garantir } \\
\text { rentabilidade dos projetos } \\
\text { e, consequentemente, da } \\
\text { organização }\end{array}$ & $\begin{array}{l}\text { Como uma organização de } \\
\text { P\&D com projetos de longa } \\
\text { duração, esta organização } \\
\text { decidiu adotar o funil de } \\
\text { desenvolvimento e vem } \\
\text { aprimorando suas técnica } \\
\text { de avaliação dos projetos, } \\
\text { a medida que os projetos } \\
\text { avançam no funil }\end{array}$ & $\begin{array}{l}\text { Apesar de ter atuação } \\
\text { semelhante ao caso A, } \\
\text { PPM ainda está pouco } \\
\text { estruturado, com grande } \\
\text { dependência do estágio de } \\
\text { maturidade dos clientes. } \\
\text { Percepção do entrevistado } \\
\text { sobre relação entre } \\
\text { qualidade do PPM dos } \\
\text { clientes com qualidade dos } \\
\text { projetos indica que o PPM } \\
\text { deveria ser estruturado para } \\
\text { toda a organização }\end{array}$ & $\begin{array}{l}\text { Processo de seleção pouco } \\
\text { criterioso, pouca clareza } \\
\text { sobre a prioridade dos } \\
\text { projetos e demanda por } \\
\text { recursos capacitados } \\
\text { acima da disponibilidade } \\
\text { geram conflitos, alocação } \\
\text { indevida dos recursos, } \\
\text { atrasos durante a execução } \\
\text { dos projetos }\end{array}$ \\
\hline
\end{tabular}

\subsection{Avaliações dos projetos}

Todos os casos realizam avaliações individuais dos projetos, com perspectivas e níveis de profundidade diferentes. Nos casos A e C, há uma avaliação para elaboração de proposta comercial para clientes. No entanto, no caso A esse processo é muito mais estruturado, com um questionário detalhado do que deve ser avaliado em cada situação. No caso C, essa análise é ad hoc, dependendo do cliente e da experiência da equipe que realiza a avaliação. No caso B são realizadas diferentes avaliações em cada uma das três fases com base no modelo de Wheelwright e Clark (1992). No caso D, apenas os projetos estratégicos têm uma avaliação mais criteriosa, com apoio de consultorias especializadas em alguns casos.

\subsection{Seleção e priorização de projetos}

Nenhum dos casos realiza essa etapa de forma efetiva. Os casos A e C justificam a ausência de um processo de seleção e priorização eficaz indicando que têm interesse em incentivar o aumento de projetos, pois eles representam uma importante parcela da receita. 0 caso B não relatou restrição de recursos, portanto pode dar andamento em todos os projetos com viabilidade técnica e aderentes aos objetivos estratégicos. 0 caso $D$ faz uma priorização superficial que não é seguida durante a etapa de execução.

\subsection{Alocações de recursos}

Realizado de forma satisfatória nos casos A e B. No caso $C$, há uma alocação inicial que muda com frequência devido ao excesso de projetos e falha no planejamento destes. No caso $\mathrm{D}$, como as restrições de recursos humanos não são consideradas durante a alocação, há uma "guerra por recursos" durante a execução.

\subsection{Controles do portfólio}

É realizado de forma mais criteriosa nos casos A e C devido à existência do PMO. No entanto, no caso A o PMO tem uma função mais estratégica, com foco nos principais projetos e com o objetivo de apoiar na solução de eventuais problemas encontrados durante a execução desses projetos. No caso C, o PMO tem um papel bastante operacional, com o acompanhamento de todos os projetos e geração de relatórios e apresentações para que as equipes responsáveis tomem as providências necessárias. No caso B, o controle é feito pelo gerente executivo, de forma ad hoc, e no caso D o controle é maior nos projetos estratégicos, mas não há um processo comum para gerenciar os conflitos.

\section{Considerações finais}

Os modelos de PPM propostos por Wheelwright e Clark (1992) eCooper, Edgett e Kleinschmidt (1997b) são adequados para organizações com ênfase em projetos de desenvolvimento de produtos e/ou projetos de médio e longo prazo, como o caso B. Para essas organizações, os dois modelos podem ser utilizados como base para desenvolvimento de seu processo de PPM, extraindo do primeiro as dimensões de categorização e avaliação individual de projetos e a estudo dos recursos disponíveis para seleção dos projetos (Quadro 1). 
No entanto, esses dois modelos dão pouca ênfase ao controle do portfólio e da utilização de informações sobre os projetos em andamento no PPM, que é um dos destaques do modelo de Archer e Ghasemzadeh (1999), que incorpora práticas de revisão dos projetos em andamento e utiliza as informações desses projetos na avaliação dos novos projetos do portfólio. Esse modelo é bastante útil para organizações, cujo portfólio é mais dinâmico, como os casos A, C e D, com grande volume de projetos de curto prazo, nos quais a alocação de equipes é complexa e crítica para o sucesso dos projetos.

0 modelo do PMl (2006) mostrou-se mais superficial que os demais ao discutir os estágios e apresentar as ferramentas e atividades que devem ser executadas. Já o modelo proposto por Rabechini Jr., Maximiano e Martins (2005) dá mais ênfase à gestão operacional do portfólio de projetos em execução, que não faz parte do escopo desta pesquisa.

Em síntese, o estudo permitiu verificar que não existe um único processo ou método de PPM eficaz para todas as organizações. Os responsáveis por implementar o processo de PPM em uma organização devem conhecer bem as necessidades de sua organização e os modelos de PPM já desenvolvidos e escolher quais etapas e técnicas são mais adequadas.

A análise do estágio de implementação das práticas de PPM foi realizada com a separação das organizaçõesquerealizamPPM de forma padronizada (casos A e B) e aquelas em que há predominância de procedimentos ad hoc (casos C e D). Os casos A e C mostram a diferença entre um processo de avaliação de projetos estruturados, realizados com boa visibilidade dos recursos disponíveis (caso A), e outro onde esse processo ocorre de forma superficial (caso C). 0 caso D mostra uma situação crítica, onde há um processo de planejamento estratégico bem estruturado, mas, devido à baixa visibilidade dos projetos em andamento e dos recursos disponíveis, perde parte do seu valor com o atraso e a falta de qualidade dos principais projetos da organização.

Este estudo indica que o PPM ainda é pouco estruturado, apresentando lacunas com relação aos modelos teóricos de referência. Estas podem dificultar a implementação adequada das ações estratégicas definidas pelas organizações. 0 desdobramento das ações estratégicas em projetos, bem como a delegação de responsabilidade pela execução deles aos níveis inferiores, de forma desestruturada, promove conflitos desnecessários, com perda de energia da organização, como foi percebido nas análises dos casos C e D.
Este estudo apresenta contribuições práticas aos executivos e gestores de PPM, com a sintese dos principais modelos e uma avaliação em face dos principais estágios do processo de PPM. De forma geral, podemos entender que as organizações estudadas, apesar de já implementarem conceitos de gerenciamento de projetos, ainda estão em um estágio inicial de utilização das práticas de PPM propostas pelos modelos teóricos. Para apoiar de uma forma mais efetiva a utilização dessas práticas pelas organizações, seria interessante que a academia avançasse no desenvolvimento de modelos que apoiem definição de uma jornada de implementação, com estágios de evolução definidos de acordo com as necessidades de cada organização.

No entanto, a pesquisa oferece limitações relacionadas ao método escolhido, à quantidade de casos estudados e à profundidade de cada um deles. Devido às limitações apresentadas, recomenda-se a realização de outros estudos que possam aprofundar a análise dos resultados obtidos nesta pesquisa.

\section{Referências}

ANTHONY, R. N. Planning and Control Systems: a framework for analysis. Cambridge: Harvard University Press, 1965.

ARCHER, N. P.; GHASEMZADEH, F. An integrated framework for project portfólio selection. International Journal of Project Management, v. 17, n. 4, p. 207-216, 1999.

CLARK, K. B.; WHEELWRIGHT, S. Managing new product and process development: text and cases. New York: The Free Press, 1993.

COOPER, R. G.; EDGETT, S. J.; KLEINSCHMIDT, E. J. Portfólio management in new product development: lessons from the leaders - 1. Research Technology Management, v. 40, n. 5, p. 16-19, 1997a.

COOPER, R. G.; EDGETT, S. J.; KLEINSCHMIDT, E. J. Portfólio management in new product development: lessons from the leaders - 11. Research Technology Management, v. 40, n. 6, p. 43-52, 1997b.

COOPER, R. G.; EDGETT, S. J.; KLEINSCHMIDT, E. J. Portfólio management for new product development: results of an industry practices study. $R \& D$ Management, v. 31 , n. 4, p. 61-380, 2001.

DE REYCK, B. et al. The impact of project portfólio management on information technology projects. International Journal of Project Management, v. 23, n. 7, p. 524-537, 2005.

DIETRICH, P.; LEHTONEN, P. Sucessful management of strategic intentions through multiple projects Reflections from empirical study. International Journal of Project Management, v. 23, n. 5, p. 386-391, 2005.

DYE, L. D.; PENNYPACKER, J. S. Project portfólio management. selecting and prioritizing projects for competitive advantage. West Chester: Center for Business Practices, 1999.

HAIR Jr., J. F. et al. Fundamentos de métodos de pesquisa em administração. Porto Alegre: Bookman, 2005.

JEFFERY, M.; LELIVELD, 1. Best Practicies in IT Portfólio Management. MIT Sloan Management Review, v. 45, n. 3, p. 41-49, 2004. 
KERZNER, H. Gestão de Projetos: as melhores práticas. Porto Alegre: Bookman, 2002.

KRUGLIANSKAS, 1. Planejamento do centro de tecnologia empresarial cativo. In: VASCONCELLOS, E. (Ed.) Gerenciamento da tecnologia: um instrumento para a competitividade empresarial. São Paulo: Edgar Blucher, 1992. p. 39-96.

LOVE, P. E. D.; IRANI, Z.; EDWARDS, D. J. Learning to Reduce Rework in Projects: Analysis of Firm's Organizational Learning and Quality Practices. Project Management Journal, v. 34, n. 3, p. 13-29, 2003.

PROJECT MANAGEMENT INSTITUTE - PMI. A Guide to the Project Management Body of Knowledge (PMBOK). Philadelphia, 1996.

PROJECT MANAGEMENT INSTITUTE - PMI. A Guide to the Project Management Body of Knowledge (PMBOK). 2. ed. Maryland, 2000.

PROJECT MANAGEMENT INSTITUTE - PMI. A Guide to the Project Management Body of Knowledge (PMBOK). 3. ed. Maryland, 2004.
PROJECT MANAGEMENT INSTITUTE - PMI. A Guide to the Project Management Body of Knowledge (PMBOK). 4. ed. Maryland, 2008.

PROJECT MANAGEMENT INSTITUTE - PMI. The Standard for Portfólio Management. Maryland: Project Management Institute Inc., 2006.

RABECHINI Jr., R.; MAXIMIANO, A. C. A.; MARTINS, V. A. A adoção de portfólio como uma alternativa gerencial: o caso de uma empresa prestadora de serviço de interconexão eletrônica. Revista da Produção, v. 15, n. 3, p. 416-433, 2005.

ROUSSEL, P. A.; SAAD, K. N.; BOHLIN, N. Pesquisa e Desenvolvimento: como integrar $\mathrm{PAD}$ ao plano estratégico das empresas como fator de produtividade e competitividade. São Paulo: Makron Books, 1992.

WHEELWRIGHT, S. C.; CLARK, K. B. Creating Project Plans to Focus Product Development. Harvard Business Review, v. 70, n. 2, p. 70-83, 1992.

YIN, R. K. Estudo de caso: planejamentos e métodos. 3. ed. São Paulo: Bookman, 2005.

\title{
Project Portfolio Management (PPM): case studies
}

\begin{abstract}
This article consists of a review of the literature on the main PPM models, in addition to a critical analysis to build a theoretical framework. Four case studies are presented of companies from different sectors, which aim to identify the main PPM practices adopted, their implementation stage and the relations between those practices and the benefits obtained. The main research results show that PPM is still rarely present in organizations. The lack of PPM may be one of the factors hampering the correct implementation of strategic actions defined by the executive team. The deployment of strategic actions in projects and the structureless delegation of responsibility for implementation to mid-level managers creates unnecessary conflicts, with a consequential loss of an organization's energy.
\end{abstract}

\section{Keywords}

Project Management. Project Portfolio Management. Project Selection. 